\title{
Militärischer Verrat und »nationale Tat $«$. Die konspirative Vorbereitung des Posener Aufstands durch polnisch-preußische Soldaten im Sommer und Herbst 1918
}

von

JENS BOYSEN

Abstract: Die Niederlage Deutschlands im Jabre 1918 löste nicht nur die Novemberrevolution aus, sondern auch eine Mobilisierung der polnischen Bevölkerung im preuBischen Osten mit der letztlichen Folge einer Abspaltung mehrerer Provinzteile vom Deutschen Reich. Eine Voraussetzung hierfür waren Spannungen, die nach der Reichsgründung 1871 infolge einer Verengung des gesellschaftlichen Toleranzbegriffs und von Diskriminierungen nationaler Minderbeiten eingetreten waren. Die Polen entwickelten daraufhin eine Art Parallelgesellschaft; aber nur kleine radikale Gruppen unter ibnen hegten vor dem Ersten Weltkrieg separatistische Absichten. Den Krieg machten die Polen als Soldaten und Zivilisten ebenso mit wie die Deutschen, wenn auch mit deutlich weniger Enthusiasmus. Zugleich förderte das politische Werben der kriegführenden Hauptmächte um die Polen (und andere staatenlose Völker) bei diesen nationalstaatliche Bestrebungen. Aber erst angesichts des deutschen Scheiterns im Herbst 1918 traten die Polen im Deutschen Reich mit entsprechenden Forderungen hervor. In der Provinz Posen als dem Zentrum der polnischen Nationalbewegung wirkte seit dem Sommer 1918 innerhalb der lokalen militärischen Einheiten eine nationalpolnische Konspiration, die zum einen preußische Sicherungsmaßnabmen sabotierte bzw. manipulierte und zum anderen eigene Kommandostrukturen für den Fall eines Zusammenbruchs der staatlichen Macht aufbaute. Diese Soldaten wirkten mit zivilen polnischen Politikern bei der Täuschung der preußischen und Reichsbehörden zusammen, konkurrierten aber zugleich mit ibnen um die Führungsrolle. All diese überwiegend konservativ gesinnten Gruppen teilten jedoch kaum die "roten "normativen Ziele der Novemberrevolution, sondern saben in dieser vor allem eine günstige Gelegenheit für eine eigene "nationale Revolution". Aus dieser komplexen Lage heraus erfolgte am 27. Dezember 1918 der Ausbruch des "Großpolnischen Aufstands", der die Provinz Posen unter polnische Kontrolle brachte und die Westmächte gegenüber weiteren polnischen Gebietsforderungen geneigt machen sollte.

Am 27. Dezember 1918 kam es in Posen, der Hauptstadt der gleichnamigen preußischen Provinz - die von ihren polnischen Bewohnern »Großpolen« (Wielkopolska) genannt wurde - zu einem bewaffneten Aufstand polnischer Verbände, denen es in kurzer Zeit gelang, die Kontrolle über fast die ganze Stadt zu erlangen. Auslöser dieses Geschehens - in einer noch näher zu beschreibenden Weise - war der am Vortag begonnene Besuch des polnischen Pianisten und Politikers Ignacy Paderewski als Vertreter des von den West- 
mächten anerkannten Polnischen Nationalkomitees (Komitet Narodowy Polski - KNP) in Paris. Obwohl der am 11. November 1918 in Compiègne geschlossene Waffenstillstand zwischen der Entente und Deutschland die deutsche Hoheit auch in den von den Polen beanspruchten preußischen Ostgebieten intakt ließ ${ }^{1}$, bedeuteten Paderewskis Landung in Danzig und seine Eskortierung nach Posen (unter britischem Schutz) eine klare Unterstützung der polnischen Ansprüche im Hinblick auf die bevorstehende Friedenskonferenz in Paris. Dabei änderte Paderewski trotz deutscher Proteste eigenmächtig seinen Reiseweg, der ihn eigentlich von Danzig direkt nach Warschau führen sollte. Durch sein Auftreten in Posen sollte das besagte KNP in seiner Eigenschaft als offizielle Vertretung der bis dahin staatenlosen Polen gestärkt werden, zum einen gegenüber Deutschland, zum anderen aber gegenüber dem »linken « - tatsächlich eher als >nationalrevolutionär $\iota^{2}$ zu bezeichnenden - politischen Lager um Józef Piłsudski, das im Oktober 1918 in Warschau und Galizien die politische Macht übernommen hatte ${ }^{3}$. Piłsudskis Gegenspieler war der Vorsitzende des KNP und Führer der rechtsnationalistischen Nationaldemokraten (Endecja), Roman Dmowski'; er war der Gewährsmann vor allem der französischen Regierung, die sich über ihn einen langfristigen Einfluss auf die strategische Entwicklung in Ostmitteleuropa versprachen ${ }^{5}$. Piłsudski dagegen, der seit 1914 an der Seite der Habsburgermonarchie und ab Sommer 1915 im deutsch besetzten Warschau aktiv gewesen und schließlich im Juli 1917 von den deutschen Militärbehörden inhaftiert worden war, besaß in der polnischen Öffentlichkeit viel größeres Ansehen als Dmowski und war überdies den Westmächten nichts schuldig. Während es sinnlos erschien, Pilsudski in den schon von ihm beherrschten Gebieten herauszufordern, sollte Paderewskis Besuch im »preußischen Teilungsgebiet ${ }^{6}$, dessen Schicksal in den Händen der Westmächte lag, den Nationaldemokraten eine führende Stellung sichern.

Anders als in Elsass-Lothringen, das schon damals unmittelbar Frankreich unterstellt wurde.

2 Damit ist eine Haltung gemeint, die teilweise antibürgerliche Argumente aufnahm, aber in erster Linie einen militanten und »heroischen « (aber meist nicht völkischen) Gemeinschaftsbegriff beschwor. Zur Definition am deutschen Beispiel, für das v.a. Ernst Jünger stand, vgl. Armin Mohler, Die Konservative Revolution in Deutschland 1918-1932, Darmstadt 1994, S. 142-146, sowie Kurt Sontheimer, Antidemokratisches Denken in der Weimarer Republik, München, 4. Aufl. 1994, S. 93-111.

3 Zur Entwicklung dieser polnischen Variante eines heroisch-vitalistischen Führerkults vgl. Heidi Hein-Kircher, Der Pilsudski-Kult und seine Bedeutung für den polnischen Staat 1926-1939, Marburg 2001.

4 Vgl. zu dieser Rivalität allgemein Roman Wapiński, Rola Piłsudskiego i Dmowskiego w odbudowie państwowości [Die Rolle Piłsudskis und Dmowskis beim Aufbau der Staatlichkeit]. In: Życie polityczne w Polsce 1918-1939, Wrocław u. a. 1985 (Najnowsze Osiągnięcia Nauki), S. 7-30.

5 Vgl. Andrzej Kwilecki/Władysław Tomaszewski, Poznań jako ośrodek polskiej myśli zachodniej w dwudziestoleciu międzywojennym [Posen als Zentrum des polnischen Westgedankens in den 20 Jahren der Zwischenkriegszeit]. In: Polska myśl zachodnia w Poznaniu i Wielkopolsce. Jej rozwój i realizacja w wiekach XIX i XX, Warszawa/Poznań 1980, S. 129-184, hier S. 95.

6 Polnisch »zabór pruski«, Bezeichnung für die 1815 zu Preußen gekommenen ehemals polnischen Gebiete. 
Im Januar 1919 weitete sich die Posener Aufstandsbewegung über den Großteil der Provinz aus - daher wird sie im Polnischen als »Großpolnischer Aufstand « (Powstanie Wielkopolskie) bezeichnet - und konnte erst im als Netzedistrikt bekannten Nordteil der Provinz zwischen Schneidemühl (Piła) und Bromberg (Bydgoszcz) von deutschen Truppen und Eisenbahnern zum Halten gebracht werden. Am 16. Februar 1919 wurde eine Demarkationslinie festgelegt, danach blieb die Lage über mehrere Monate hinweg relativ stabil, wobei es zu zahlreichen lokalen Grenzscharmützeln kam. Ein geplanter deutscher Gegenstoß wurde im Mai 1919 von den Ententemächten untersagt, so dass die polnischen Aufständischen die besetzten Gebiete halten konnten. Im Versailler Vertrag vom 28. Juni 1919 wurde dem neuen polnischen Staat dann nicht nur fast die gesamte Provinz Posen zugesprochen, sondern auch das mehrheitlich deutsche Westpreußen, um ihm den in Präsident Woodrow Wilsons »Vierzehn Punkten« zugesagten Zugang zum Meer zu verschaffen; am 20. Januar 1920, dem Tag des Inkrafttretens des Vertrages, übernahm Polen auch die bis dahin noch deutsch kontrollierten Gebiete Posens und Westpreußens.

So komplex die Umwälzungen des Jahres 1919 im preußischen Osten waren und so viele offene Fragen hierzu bis heute bestehen, die großpolnische Erhebung vom Dezember 1918 war jedenfalls die Initialzündung dafür. Daher ist es nicht verwunderlich, dass die Nationaldemokraten den Aufstand in der Folge sich zuschrieben und als ihren Beitrag zur »Befreiung der polnischen Lande « darstellten. Der Zusammenhang mit Paderewskis Besuch schien offenkundig, und das Ergebnis entsprach den Wünschen sowohl der Endecja als auch der französischen Führung. In den dann »westpolnischen « (zachodniopolskie) Gebieten blieben die Nationaldemokraten in der Zweiten Republik (1919-1939) die führende politische Kraft; zugleich betrieben sie eine administrative »Entdeutschung «", was diese Region zur, wie es explizit genannt wurde, »national reinsten « ganz Polens machte ${ }^{8}$. In der innerpolnischen Debatte wurde die nationaldemokratische Darstellung des Aufstands allerdings von Beginn an von rivalisierenden politischen Kräften in Frage gestellt, in erster Linie von Unterstützern Piłsudskis, darunter nicht zuletzt Vertreter der polnischen Legionen, jener Freischärlerverbände, die Piłsudskis physische und moralische Machtbasis bildeten. Sie beanspruchten den Aufstand für sich, d.h. sie erklärten die maßgeblichen Verschwörer zu Anhängern Piłsudskis und sahen den >Sinn < des Aufstands in der Vorbereitung des Anschlusses an den neuen, von ihrem »Kommandanten« gelenkten polnischen Staat ${ }^{9}$.

Polnisch »odniemczanie«, ein bei polnischen nationalistischen Politikern und Behörden damals üblicher Ausdruck. Er wurde deutscherseits u. a. von Hermann Rauschning in seinem Buch »Die Entdeutschung Westpreußens und Posens. Zehn Jahre polnischer Politik« (Berlin 1930) übernommen.

8 Zbigniew Dworecki, Mniejszość niemiecka w Poznaniu w latach II Rzeczypospolitej [Die deutsche Minderheit in Posen in den Jahren der Zweiten Republik]. In: Niemcy i Żydzi w Poznaniu (Kronika Miasta Poznania, 1-2/1992), Poznań 1992, S. 37-66, hier S. 44.

9 Vgl. für dieses Umfeld Zygmunt Wieliczka, Od Prosny po Rawicz. Wspomnienia z Powstania Wielkopolskiego 1918-1919 [Von der Prosna nach Rawitsch. Erinnerungen aus dem Großpolnischen Aufstand 1918-1919], Poznań 1931. 


\section{Historische Bewertung des Aufstands}

Wie relevant der Posener Aufstand tatsächlich für die weitere politische Entwicklung gewesen ist, war und ist in der Geschichtswissenschaft umstritten ${ }^{10}$. Mit ihm beschäftigen sich allerdings, jedenfalls seit 1945, fast nur polnische Historiker; in Deutschland ist das Geschehen in der damaligen Peripherie des Reiches heute weitgehend unbekannt. Offensichtlich haben die weit gravierenderen Folgen des Zweiten Weltkriegs die kollektive Erinnerung an die schon 1919/20 verlorenen Gebiete weitgehend verschüttet. Bezeichnenderweise stammt die einzige explizit dem Thema gewidmete deutsche Darstellung von Dietrich Vogt aus dem Jahr 1980; der Autor war aus Posen gebürtig und als Offizier selbst Beteiligter der Ereignisse gewesen. In den 1980er und 1990er Jahren entstanden einige wenige relevante Arbeiten zum Thema, die den Aufstand eher kursorisch und in der Regel in einem weiteren Kontext thematisieren, aber nicht als $>$ Ereignis $<$ im $>$ polnischen $<$ Stil ${ }^{11}$. Bei einer parallelen Betrachtung zur Bedeutung des Kriegsendes von 1918 aus dem Jahr 1993 wurde der Aufstand nur vom polnischen Autor erwähnt, nicht dagegen vom deutschen ${ }^{12}$. Auch das schon ältere, aber noch immer wichtige Werk von Francis L. Carsten über die »Revolution in Mitteleuropa « (womit das Deutsche Reich und Österreich-Ungarn gemeint sind) benennt zwar den wichtigen Einfluss der 1918 entstandenen Arbeiter- und Soldatenräte auf das Geschehen im Posenschen, erwähnt aber den Aufstand selbst gar nicht ${ }^{13}$. Ein - im Prinzip sehr guter Aufsatz in der ersten Ausgabe des Journal of Modern European History von 2003 zu den Auswirkungen des Ersten Weltkriegs auf die Gewaltbereitschaft der damaligen europäischen Gesellschaften betrachtet Deutschland, erwähnt aber die Spezifik des preußischen Ostens nicht ${ }^{14}$. Erst in jüngster Zeit hat sich

10 Vgl. dazu Dietrich Vogt, Der Großpolnische Aufstand 1918/1919. Berichte-ErinnerungenDokumente, Marburg 1980, S. 1-5.

11 Roland Baier, Der deutsche Osten als soziale Frage. Eine Studie zur preußischen und deutschen Siedlungs- und Polenpolitik in den Ostprovinzen während des Kaiserreiches und der Weimarer Republik, Köln u.a. 1980, besonders S. 176-201; Rainer Schumacher, Die Preußischen Ostprovinzen und die Politik des Deutschen Reiches, 1918-1919. Die Geschichte der östlichen Gebietsverluste Deutschlands im politischen Spannungsfeld zwischen Nationalstaatsprinzip und Machtanspruch, Köln 1985; Ralph Schattkowsky, Deutschland und Polen 1918/19 bis 1925. Deutsch-polnische Beziehungen zwischen Versailles und Locarno, Frankfurt a. M. u. a. 1994, S. 21-48; Georg W. Strobel, Denken und Handeln in den polnischen Teilungsgebieten und in Polen nach 1918. In: Zeitschrift für Ostmitteleuropaforschung 44 (1995), 2, S. 191-270, besonders S. 236-242; Arnon Gill, Eine tragische Staatsgrenze. Geschichte der deutsch-polnischen Grenze von 1918-1945, Frankfurt a. M. u. a. 1997, S. 19-31.

12 Vgl. Jerzy Holzer und Andreas Lawaty [bei beiden Autoren gleichlautender Titel], 1918: Das Ende des Ersten Weltkrieges, Deutschlands Zusammenbruch und die erste Wiederherstellung des polnischen Staates. In: Wendepunkte der deutsch-polnischen Beziehungen im 20. Jahrhundert: 1918 - 1939 - 1945 - 1990, hrsg. von Rex Rexheuser, Lüneburg 1993, S. 7-18 bzw. 19-34.

13 Francis L. Carsten, Revolution in Mitteleuropa 1918-1919, Göttingen 1973, S. 218-222.

14 Benjamin Ziemann, Germany after the First World War - A Violent Society? Results and Implications of Recent Research on Weimar Germany. In: Journal of Modern European History, 1 (2003), 1: Violence and Society after the First World War, S. 80-95. 
die Forschung zu den Nachkriegskämpfen - unter anderem - in Ostmitteleuropa stärker entwickelt, gerade auch als gewaltsame Prägefaktoren für die Herausbildung neuer Staaten ${ }^{15}$.

In Polen dagegen bildete nach 1919 und bildet bis heute jener »einzige erfolgreiche nationale Aufstand « einen zentralen Erinnerungsort (lieu de mémoire $)^{16}$, der sowohl in der Zweiten Republik als auch in der Polnischen Volksrepublik (Polska Rzeczpospolita Ludowa ${ }^{17}$ ) seit 1944/45 regelmäßig bemüht wurde. Vor 1939 wurde diese Erinnerung in der angedeuteten Weise vor allem von den Posener Nationaldemokraten dazu genutzt, den politischen Stellenwert der ehemals preußischen Gebiete innerhalb des überwiegend - und seit dem Maiumsturz von 1926 völlig - von den Piłsudski-Anhängern beherrschten Staates zu erhöhen ${ }^{18}$. Dabei übernahmen die im Allgemeinen sgut bürgerlichen< Nationaldemokraten die nationalrevolutionäre Terminologie ihrer Kontrahenten und priesen die »bewaffnete Tat « (czyn zbrojny) der Großpolen von 1918/19, die wiederum die Konsequenz eines langen allgemeinen Strebens nach Loslösung von Preußen gewesen $\operatorname{se}^{19}$.

Nach 1945, als Polen erneut umfangreiche deutsche Gebiete erhalten hatte, diente dieses Narrativ dann primär zur Etablierung der antideutschen und prosowjetischen Staatsraison des kommunistischen Polen; dabei erwies sich die nationalistische (und nach marxistischen Maßstäben eigentlich »reaktionäre«) Endecja-Ideologie als bemerkenswert anschlussfähig. Deren Vertreter erhielten in »Volkspolen « oft wichtige Positionen auf dem Gebiet der sstaatsbürgerlichen Erziehung ${ }^{20}$; dies war Teil einer allgemeinen Integration nationalistischer Denkmuster und Bilder in die kommunistische Herrschaft ${ }^{21}$. Wie relevant der Posener Aufstand in diesem Kontext war, zeigt die Tatsache, dass ab 1958 alle zehn Jahre zum Jubiläum des Ereignisses (und darüber hinaus)

15 Vgl. War in Peace. Paramilitary Violence in Europe after the Great War, hrsg. von Robert Gerwarth und John Horne, Oxford 2012 (dt. Ausgabe: Krieg im Frieden. Paramilitärische Gewalt nach dem Ersten Weltkrieg, Göttingen 2013).

16 Dieses Konzept entwickelte Pierre Nora in seinem Opus magnum Les lieux de mémoire, 7 Bde., Paris 1984-1992.

17 Offiziell hieß der kommunistische Staat erst seit 1952 so, zuvor »Polnische Republik «,

18 Vgl. Barbara Wysocka, Regionalizm wielkopolski w II Rzeczypospolitej 1919-1939 [Der großpolnische Regionalismus in der Zweite Republik 1919-1939], Poznań 1981, S. 86-116; Bastiaan Schot, Staat, Nation und territoriale Fragen im östlichen Mitteleuropa. Innere Konsolidierung und internationale Konstellation. Zur Entwicklung Polens in der Zeit zwischen den beiden Weltkriegen. In: Nationales Selbstverständnis und politische Ordnung, hrsg. von Hans Hecker und Silke Spieler, Bonn 1991, S. 51-67, hier S. 55 f.

19 Vgl. exemplarisch hierfür die Reden auf dem $\gg 1$. Kongress der Unabhängigkeitskämpfer des früheren preußischen Teilungsgebiets in Posen vom 14. Januar 1934«. In: M. Jabczyński, Pamiętnik I zjazdu niepodległościowców byłej dzielnicy pruskiej w Poznaniu 14 stycznia 1934 r., Poznań 1935 [dt. Übersetzung durch die Publikationsstelle des Geheimen Preußischen Staatsarchivs Berlin-Dahlem 1936].

$20 \mathrm{Zu}$ dieser Personengruppe vgl. Markus Krzoska, Für ein Polen an Oder und Ostsee. Zygmunt Wojciechowski (1900-1955) als Historiker und Publizist, Osnabrück 2003.

21 Zu diesem Thema s. allgemein Marcin Zaremba, Im nationalen Gewande. Strategien kommunistischer Herrschaftslegitimation in Polen 1944 - 1980, Osnabrück 2011. 
neue Darstellungen erschienen und weiter erscheinen ${ }^{22}$. Bis 1989 enthielten diese noch in gewissem Umfang Referenzen an den Marxismus, u. a. bezüglich der sozialen Zusammensetzung der Aufständischen, wobei es darum ging, einen hohen Anteil von Arbeitern und Bauern zu belegen ${ }^{23}$. In erster Linie waren sie aber von der genannten nationalistischen Sichtweise geprägt, in deren beiden zentralen Dimensionen: der Kultivierung des affirmativen Mythos der »bewaffneten Tat des großpolnischen Volkes $\aleph^{24}$ und der massiven antideutschen Ausrichtung. Viele polnische historische Arbeiten zu diesem Thema stellen daher, obwohl sie eine Fülle wertvoller Fakten liefern, vor allem auf nationale Identitätsstiftung abzielende Heldengesänge dar; und die Stadt Posen veranstaltet seit Jahren immer aufwendigere Gedenkspektakel, die jede historische Distanz vermissen lassen und den Mythos des lange ersehnten Volksaufstands weiterpflegen..$^{25}$

In jedem Fall ist zu fragen, wie es am Ende des Ersten Weltkriegs zu einem solchen gewaltsamen Zusammenstoß im vom äußeren Feind unbesetzten Osten des Deutschen Reiches kommen konnte bzw. wer die Aufständischen waren, wem sie sich politisch zugehörig fühlten und warum sie sich Mitte bzw. Ende 1918 auf ein bewaffnetes Handeln vorbereiteten. Keinesfalls lässt sich nämlich der Aufstand, an dem sich in Posen und anderen Städten der Provinz schon am 27. Dezember 1918 Tausende bewaffneter Polen beteiligten, als »spontane Massendemonstration « bezeichnen ${ }^{26}$. Ebenso wenig erscheint es sinnvoll, in einer für die ältere polnische Historiographie charakteristischen Formulierung zu behaupten, »jeder polnisch Fühlende und Denkende [habe] zu den Waffen gegriffen und sich eingereiht $\aleph^{27}$. Durch eine solche Sicht wird die Komplexität kollektiver Willensbildung und kollektiven Handelns simplifiziert und werden methodisch unreflektierte, essentialistische Sichtweisen verstetigt.

Viele Autoren unterstellen in plausibler Weise, dass dem Aufstand eine Phase der Planung und Vorbereitung vorausgegangen sein muss; es ist aber zu klären, welche zeitlichen, politischen und personellen Strukturen dabei anzu-

22 Klassisch: Antoni Czubiński, Powstanie Wielkopolskie 1918-1919. Geneza-charakter-znaczenie [Der Großpolnische Aufstand 1918-1919. Entstehung-Charakter-Bedeutung], Poznań 1978 (2. Aufl. 1988, 3. Aufl. 2002). Zur Übersicht s. den Eintrag »Großpolnischer Aufstand 19181919 in der Bibliographie Deutsch-polnische Beziehungen in Geschichte und Gegenwart 1900-1998, hrsg. von Andreas Lawaty et al., Bd. 1: Politik, Gesellschaft, Wirtschaft, Kultur in Epochen und Regionen, Wiesbaden 2000, S. 649-661.

23 Vgl. Ludwik Gomolec, Ilu stanęło do walki, kim byli walczący [Wie viele sich zum Kampf stellten und wer die Kämpfer waren]. In: Novum (Warszawa) 13 (1971), Nr. 12, S. 151-161.

24 So der Titel des Aufsatzes von Zdzisław Grot, Czyn zbrojny ludu wielkopolskiego 1918-1919. In: Wojskowe aspekty Powstania Wielkopolskiego 1918-1919. Wybór materiałów źródłowych, red. Bolesław Woszczyński, UAM w Poznaniu, Seria Historia Nr 124, Poznań 1985, S. 9-59.

25 Vgl. die Website der Stadtverwaltung Posen unter <http://www.poznan.pl/powstanie> (5. August 2015).

26 So z.B. Harald v. Riekhoff, German-Polish Relations 1918-1933, Baltimore-London 1971, S. 13.

27 Antoni Czubiński, Powstanie Wielkopolskie 1918-1919. Zarys dziejów [Der Großpolnische Aufstand 1918-1919. Historischer Abriss]. In: Zdzisław Grot/Antoni Czubiński, Powstanie Wielkopolskie 1918-1919, Poznań 2006, S. 35-94, hier S. 70. 
setzen sind. Im Hinblick auf das Leitthema dieses Bandes soll insbesondere danach gefragt werden, inwieweit von einem konspirativen Vorgang innerhalb der militärischen Strukturen bzw. an der Schnittstelle von Zivil und Militär die Rede sein kann. Für eine komplexe und im transnationalen Diskurs nutzbare Betrachtung dieser Frage sind verschiedene Dimensionen zu berücksichtigen: die weltpolitische Gesamtsituation am Ende des Ersten Weltkriegs, die maßgeblichen innerpolnischen Kräfte (diese beiden Aspekte wurden schon berührt) sowie - worum es im Folgenden vor allem gehen soll - die deutschpolnischen und die zivil-militärischen Beziehungen in Stadt und Provinz Posen vor und im Ersten Weltkrieg. Denn ohne Zweifel gehört der Posener Aufstand in die Reihe jener oben erwähnten Nachkriegskämpfe, durch die bei den bis dahin staatenlosen Völkern die Energie des Krieges in bürgerkriegsähnliche Konflikte bzw. Staatsgründungskriege ${ }^{28}$ überführt wurde. Für den vorliegenden Fall bedeutet dies, danach zu fragen, wie es im Innern der preußischen Armee ab einem bestimmten Zeitpunkt und in einem bestimmten personellen Rahmen zu konspirativen Vorgängen kommen konnte, die gegen den deutschen Staat und damit auch gegen dessen Armee ${ }^{29}$ gerichtet waren. Dabei spielt der Aspekt der (sich wandelnden) Loyalität ebenso eine Rolle wie die Frage der zumindest formalen Legalität von effektiv illoyalen Handlungen und der Stabilität bzw. Instabilität der militärischen Hierarchie.

\section{Zivil-militärische Dispositionen vor dem Ersten Weltkrieg}

Als integrale Bestandteile des preußischen Staates und seit 1871 des Deutschen Reiches wurden die östlichen Grenzgebiete, darunter die Provinz Posen, von der preußischen Armee gesichert und seit den 1890er Jahren planmäßig als Vorfeld gegen Russland ausgebaut. Die beiden wesentlichen Berührungspunkte zwischen Armee und Zivilbevölkerung waren die Präsenz der Armee in der regionalen Infrastruktur (militärische Anlagen und Versorgungswege) sowie die allgemeine Wehrpflicht. Die jungen Polen leisteten ebenso wie ihre deutschen Altersgenossen ihren Wehrdienst ohne größere spezifische Schwierigkeiten, und insgesamt gesehen nahm die polnische Bevölkerung gegenüber der Armee eine neutrale bis wohlwollende Position ein, zumal diese sich - anders als die zivilen Behörden - relativ wenig an den nationalpolitischen Auseinandersetzungen der Zeit beteiligte ${ }^{30}$. Insbesondere seit 1886 betrieb die preußi-

28 Vgl. zu diesem Komplex Der Krieg in den Gründungsmythen europäischer Nationen und der USA, hrsg. von Nikolaus Buschmann und Dieter Langewiesche, Frankfurt a. M. 2004.

29 Die Landstreitkräfte des Kaiserreichs setzten sich aus vier Heereskontingenten zusammen (Preußen, Bayern, Sachsen und Württemberg). Da praktisch alle ethnischen Polen im preußischen Heer dienten, wird dieses im Kontext der deutsch-polnischen Beziehungsgeschichte in der Regel als »deutsche Armee« betrachtet und bezeichnet.

30 Vgl. Jens Boysen, Preußische Armee und polnische Minderheit. Royalistische Streitkräfte im Kontext der Nationalitätenfrage des 19. Jahrhunderts, Marburg/Lahn 2008, S. 268-277. 
sche Regierung gegenüber der polnischen Minderheit, die als Gefahr für die nationale Homogenität des Reiches angesehen wurde, eine Politik, die zunächst auf Assimilation und später auf Exklusion abzielte und sich in verschiedenen Ausnahmegesetzen auf kulturellem und wirtschaftlichem Gebiet äußerte (Polenpolitik). Ausdruck der zunehmend antagonistischen Wahrnehmung der Verhältnisse im preußischen Osten durch die deutsche Verwaltung und viele Notabeln (weniger durch die einfache lokale Bevölkerung) war die Verwendung des an die mittelalterlichen Marken erinnernden Begriffs »Ostmark « für diese Region besonders seit den 1890er Jahren. Der 1894 gegründete Deutsche Ostmarkenverein widmete sich der Popularisierung dieser Sichtweise ${ }^{31}$.

Dennoch blieb die äußere Situation bis 1914 weitgehend ruhig, zumal die realen Effekte der Polenpolitik gering waren. Anders als in anderen europäischen Mischgebieten der damaligen Zeit gab es kaum Fälle physischer Gewaltanwendung. Grundsätzlich war der traditionelle Aufstandsgedanke nach 1871 bei den preußischen Polen weitgehend erstorben. Die repressive Reaktion besonders Russlands, aber auch Preußens und Österreichs auf die Aufstände bzw. Aufstandsversuche von 1830/31, 1846, 1848 und 1863 hatte die Polen schrittweise auch jener Rechte beraubt, die sie nach 1815 noch besessen hatten. In Absage an die opferreiche und kontraproduktive Aufstandsidee hatten sich daher in der zweiten Hälfte des 19. Jahrhunderts die verwandten Konzepte des Positivismus (in Warschau) bzw. der »organischen Arbeit « (praca organiczna, besonders in Posen) entwickelt. Diese gingen von einem zivilisatorischen, ökonomischen und politischen Entwicklungsrückstand der Polen aus, den es durch verbesserte Bildung und Organisation aufzuholen galt (nicht zuletzt durch Lernen von den » Teilungsmächten «). Erst danach sei ein staatlicher Neuanfang denkbar und legitim. Nicht zufällig entwickelten sich entsprechende Strukturen besonders erfolgreich in Preußen bzw. seit 1871 im Deutschen Reich, wo das tendenziell beste Bildungs- und Hochschulwesen, eine moderne Verwaltung sowie ein insgesamt korrekt arbeitender Rechtsstaat bestanden und wo auch die Polen Anteil an den neuesten Errungenschaften von Wissenschaft und Technik nehmen konnten ${ }^{32}$.

Vor allem nach 1900 war der Gedanke des nationalrevolutionären Kampfes von einigen polnischen Organisationen wieder kultiviert worden, nicht zuletzt in Reaktion auf den wachsenden Anpassungsdruck durch die deutschen Behörden und die daraus resultierenden politisch-sozialen Spannungen ${ }^{33}$. Dies betraf neben dem nationalpolnisch orientierten Turnerverband Sokót (Falke)

31 Vgl. Sabine Grabowski, Deutscher und polnischer Nationalismus. Der Deutsche OstmarkenVerein und die polnische Straż 1894-1914, Marburg 1998. Zu den konkurrierenden Identitätsentwürfen beider Seiten siehe Thomas Serrier, Provinz Posen, Ostmark, Wielkopolska. Eine Grenzregion zwischen Deutschen und Polen 1848 - 1914, Marburg 2005.

32 Vgl. zu diesem Komplex Maciej Janowski, Gab es im 19. Jahrhundert in Polen eine Zivilgesellschaft? Erste Überlegungen. In: Die Praxis der Zivilgesellschaft. Akteure, Handeln und Strukturen im internationalen Vergleich, hrsg. von Arnd Bauerkämper, Frankfurt a. M. 2003, S. 293-316.

33 Vgl. Janusz Wojtasik, Idea walki zbrojnej o niepodległość Polski, 1864-1907: koncepcje i próby ich realizacji [Die Idee des bewaffneten Kampfes um die Unabhängigkeit Polens 1864-1907. Konzepte und Versuche ihrer Umsetzung], Warszawa 1987, S. 132. 
vor allem verschiedene Jugendorganisationen, etwa die von Gymnasiasten gebildete geheime Tomasz-Zan-Gesellschaft (TTZ) und den Bund der Polnischen [Studentischen] Jugend (Związek Młodzieży Polskiej, bekannt als ZET) sowie seit ca. 1912 das aus England stammende und über Deutschland vermittelte Pfadfinderwesen (poln. harcerstwo bzw. skauting) ${ }^{34}$. Eine Idee, die sich in Zeugnissen mancher dieser Gruppen findet, war diejenige, durch den Wehrdienst in der preußischen Armee sowie durch eigene illegale Wehrübungen militärische Kenntnisse zu erwerben, die eines Tages für die »polnische Sache« eingesetzt werden könnten. Allerdings wären dies vor 1914 (bzw. 1918) völlig realitätsferne Vorstellungen gewesen. Wahrscheinlich hat man es daher bei entsprechenden Stimmen am Vorabend des Weltkriegs, insbesondere in dem seit 1911/12 grassierenden »Kriegsfieber «, bei der polnischen akademischen Jugend mit der gleichen Mischung aus Überdruss und romantisch-vitalistischem Tatendrang zu tun wie bei ihren Altersgenossen in den Nachbarvölkern, auch wenn die privat organisierte polnische Erziehung seit dem späten 19. Jahrhundert gern die vermeintlich »heroische« Vergangenheit des polnischlitauischen Reiches als Bezugspunkt genommen hatte ${ }^{35}$.

Die Mehrheit der polnischen Bevölkerung in Preußen-Deutschland zeigte keinerlei Neigung zu gewalttätigen Plänen. Allerdings verfolgte sie die Tätigkeit der besagten Jugendgruppen wohl nicht ohne Sympathie, jedenfalls insoweit sie diese als defensive Akte zum Erhalt der eigenen kulturellen Identität deuten konnte. Auch bewirkten - durchaus legitime und reguläre - staatliche Maßnahmen zur Unterbindung derartiger Aktivitäten eine Solidarisierung, so z.B. der sogenannte »Thorner Gymnasiasten-Prozess «, in dem 1901 gegen 35 polnische Schüler wegen Bildung einer »Geheimorganisation « Verweise und andere Strafen verhängt wurden, darunter nicht von ungefähr auch der Entzug des Rechts auf den privilegierten Heeresdienst als Einjährig-Freiwilliger ${ }^{36}$.

In diesem Zusammenhang ist auch wichtig, dass in der als »Aufstandstradition « (tradycja porestańcza) bezeichneten Strömung des politischen Denkens der Begriff »Verschwörung « (konspiracja) keinen pejorativen, sondern einen positiven Klang besaß. Darin kam die Haltung zum Ausdruck, wegen ihrer unfreiwilligen Zugehörigkeit zu einer der drei »Teilungsmächte« (polnisch zaborcy, wörtlich »Räuber «) seien die Polen moralisch nicht zur Loyalität verpflichtet und sei zugleich jedwede offene oder verdeckte Aktivität zur »nationalen Befreiung « legitimiert. Grundsätzlich ist aber die auch in jüngeren polnischen Arbeiten noch zu findende Behauptung, alle Polen hätten vor 1914, entsprechend einem messianischen Gedicht des Nationaldichters Adam Mi-

${ }^{34}$ Vgl. Vogt, Großpolnischer Aufstand (wie Anm. 10), S. 8-10, sowie den umfassenden Überblick von Janusz Karwat, Od idei do czynu. Myśl i organizacje niepodległościowe w Poznańskiem w latach 1887-1919 [Von der Idee zur Tat. Unabhängigkeitsidee und -organisationen im Posenschen in den Jahren 1887-1919], Poznań 2002, S. 181-287.

35 Vgl. Boysen, Preußische Armee (wie Anm. 30), S. 72 f.

36 Vgl. Hartmut John, Das Reserveoffizierskorps im Deutschen Kaiserreich, Frankfurt a. M. u.a. 1981, S. 235-237. 
ckiewicz $^{37}$, einen »allgemeinen Krieg für die Freiheit der Völker « herbeigesehnt $^{38}$, wissenschaftlich nicht verifizierbar sowie ethisch-pädagogisch fragwürdig.

Die besagten >Wehrsport<-Organisationen waren jedenfalls viel zu wenig zahlreich, als dass sie als repräsentativ für die polnische Allgemeinheit angesehen werden könnten ${ }^{39}$. Selbst wenn man daher ihrer vollmundigen Rhetorik glauben will, dass ihre Aktivitäten auf eine bewaffnete Insurrektion gegen den preußisch-deutschen Staat abzielten, so ist dadurch keinesfalls ein allgemeiner Sezessionswunsch der preußischen Polen belegbar und sind Aussagen über eine »langjährige ${ }^{40}$ Vorbereitung des Aufstands von 1918 wenig fundiert. Viel glaubhafter ist, dass die Polen die zerstörerische Wirkung eines Krieges fürchteten, dessen Front sich durch ihr Wohngebiet ziehen würde, sowie die Möglichkeit, Verwandte und Freunde könnten gezwungen sein, in unterschiedlicher Uniform aufeinander zu schießen ${ }^{41}$.

\section{Die Auswirkungen des Ersten Weltkriegs auf die Loyalität der preußischen Polen}

Bei Kriegsbeginn 1914 wurden die wehrpflichtigen Polen in die Armee eingezogen (wodurch die erwähnten paramilitärischen Gruppen ihre Tätigkeit weitgehend einstellen mussten), während die polnischen Betriebe und Organisationen, ebenso wie die deutschen, Teil der »Heimatfront« wurden. Da die Provinz Posen (wie auch Westpreußen und Schlesien) nach der endgültigen Abwehr des russischen Vormarsches Anfang 1915 vom direkten Kampfgeschehen verschont blieb, bestand die hauptsächliche Auswirkung des Krieges in der Übernahme der öffentlichen Gewalt durch die Militärbehörden, die vereinzelt in den ersten Tagen zur Vorbeugung von Sabotageakten neben Sozialisten und Anarchisten auch polnische Minderheitenaktivisten vorübergehend festnahmen. Diese Maßnahmen wurden, da sich keine Beweise finden ließen, schnell beendet, danach gab es kaum mehr nennenswerte Störungen des Kriegsalltags, jedenfalls nicht aus nationalitätenpolitischen Gründen. Feststellbar ist aber, dass die polnische Bevölkerung den Krieg ohne große Begeisterung mit-

37 Es handelt sich um die sogenannte »Litanei der Pilgerschaft«, einen Teil der »Bücher des polnischen Volkes und der polnischen Pilgerschaft« (Księgi narodu polskiego i pielgrzymstwa polskiego) von 1832.

38 So z.B. bei Karwat, Od idei do czynu (wie Anm. 34), S. 288, dessen Arbeit jene typische Ambivalenz von Rationalität und Mythologisierung aufweist.

39 Ders., S. 286, spricht für den Zeitraum 1910-1914 von ca. 900 »illegal tätigen Polen« in ganz Deutschland, von denen 500-600 im Rahmen des Skaut oder ZET eine paramilitärische Ausbildung erhalten hätten.

40 So auch von deutscher Seite Rauschning, Entdeutschung (wie Anm. 7), S. 35, und Vogt, Großpolnischer Aufstand (wie Anm. 10), S. 8 und 11.

41 In diesem Sinne äußerte sich z.B. im Jahre 1912 der Posener Skaut-Aktivist Karol Rzepecki, vgl. Boysen, Preußische Armee (wie Anm. 30), S. 279 f. 
machte; die Spannungen der Vorkriegszeit waren zwar weit unter der Schwelle gewaltsamer Konflikte geblieben, hatten die Begeisterungsfähigkeit der Polen für das sfremde< Vaterland jedoch stark reduziert. Polnische Presse und Organisationen kamen ihren Pflichten als deutsche Staatsbürger daher nur in >minimalistischer<Weise nach ${ }^{42}$. Die ethnisch polnischen Soldaten verhielten sich aber grundsätzlich loyal. Ihre Desertionsrate schwankte zwar und war gerade in den ersten Monaten des Krieges relativ hoch, lag aber auf die Gesamtdauer des Krieges bezogen nicht über dem Durchschnitt; zudem war nur ein kleiner Teil der tatsächlichen Überläufer gewillt, für die Ententemächte zu kämpfen ${ }^{43}$. Eine bestimmte Zahl von Deserteuren versteckte sich seit Ende 1915 vor allem in der westpreußischen Tucheler Heide und griff gelegentlich öffentliche Einrichtungen $\mathrm{an}^{44}$; dies hatte aber keine größere Bedeutung. Einzelne Selbstzeugnisse polnischer Soldaten mit bürgerlich-akademischem Hintergrund, die eine nationalpolnische und antideutsche Haltung samt Unabhängigkeitsideen zeigen, können nicht als repräsentativ für die überwiegend bäuerliche preußisch-polnische Bevölkerung gelten ${ }^{45}$. Nach 1918 bzw. 1945 in Polen im staatlichen Auftrag angefertigte 'Sammelerinnerungen<, die bei allen ethnisch polnischen Soldaten des deutschen Heeres ein durchgängiges Sezessionsstreben suggerieren, sind daher mit Zurückhaltung zu rezipieren. ${ }^{46}$

Befördert wurde eine Aktivierung nationalpolnischen Denkens allerdings durch die seit Ende 1915 einsetzende propolnische Politik der Mittelmächte im besetzen Russisch-Polen, die in der Proklamation eines »Königreichs Polen« am 5. November 1916 gipfelte. Da zugleich karitative Aktionen der preußischen zugunsten der russischen Polen geduldet wurden, kam es zu einem intensivierten grenzüberschreitenden Austausch und forderten polnische Vertreter eine Aufhebung der in Preußen geltenden Ausnahmegesetze. Noch untergeordnet war die Idee eines Anschlusses Posens an den neuen polnischen Staat, jedoch wuchs seit 1916 der Einfluss der deutschfeindlichen Endecja, die

42 Vgl. Jens Boysen, Zivil-militärische Beziehungen in den preußischen Ostprovinzen Posen und Westpreußen während des Ersten Weltkriegs. In: Besetzt, interniert, deportiert. Der Erste Weltkrieg und die deutsche, jüdische, polnische und ukrainische Zivilbevölkerung im östlichen Europa, hrsg. von Alfred Eisfeld, Guido Hausmann und Dietmar Neutatz, Essen 2013, S. 127151.

43 Vgl. hierzu Jens Boysen, Nationale Minderheiten (Polen und Elsass-Lothringer) im deutschen Heer während des Ersten Weltkriegs. In: Über den Weltkrieg hinaus: Kriegserfahrungen in Ostmitteleuropa 1914-1921, hrsg. v. Joachim Tauber, Lüneburg 2009, S. 108-136; Alexander Watson, Fighting for Another Fatherland: The Polish Minority in the German Army, 19141918, in: English Historical Review, vol. CXXVI, no. 522 (November 2011), S. 1137-1166

44 Vgl. Paweł Kosiński, Prusy Zachodnie 1914 - Pomorze 1920. Ludność regionu wobec przemian politycznych okresu I wojny światowej [Westpreußen 1914 - Pomorze 1920. Die Bevölkerung der Region gegenüber den Veränderungen in der Zeit des Ersten Weltkriegs], Warszawa 2002, S. $41 \mathrm{f}$.

45 Zwei Beispiele hierfür sind Wojciech Jacobson, Z armią Klucka na Paryż [Mit der Armee von Kluck auf Paris], Toruń 1934, sowie Jozef Iwicki, Z myślą o Niepodległej, Listy Polaka-żołnierza armii niemieckiej z okopów I wojny światowej, 1914-1918 [Mit dem Gedanken an das Unabhängige [Polen]. Briefe eines Polen und Soldaten der deutschen Armee aus den Gräben des Ersten Weltkriegs, 1914-1918], Wrocław 1978.

46 Vgl. Boysen, Preußische Armee (wie Anm. 30), S. 279. 
eine solche Sezession wünschte. Sie setzte dabei, besonders durch die Tätigkeit des KNP in Paris, ihre Hoffnungen zunehmend auf die Westmächte, die sich ihrerseits für die staatenlosen Völker als Hebel zur Unterminierung der Mittelmächte zu interessieren begannen. Eine erste Manifestation der nationaldemokratischen Agitation im Reich und zugleich einer schwankenden deutschen Politik, die diese effektiv begünstigte, war die Duldung von Gedenkfeiern für den 1916 verstorbenen Literaturnobelpreisträger Henryk Sienkiewicz, der in der Schweiz antideutsche Propaganda betrieben hatte, sowie 1917 zum 100. Todestag von Tadeusz Kościuszko, der die Aufstandstradition verkörperte. Gleichwohl ist der Grad der Politisierung der preußischen Polen, zumal auf dem Lande, schwer einzuschätzen. Viel spricht dafür, dass der Großteil der preußischen Polen erst im letzten Kriegsjahr anfing, über seine politische $\mathrm{Zu}$ kunft nachzudenken und die nationalpolnische Perspektive als sinnstiftenden Ausweg aus der deutschen Niederlage erkannte ${ }^{47} .1916$ gründeten die rechten, nationalistischen polnischen Parteien in Posen ein geheimes - da illegales Interparteiliches Bürgerkomitee (Międzypartyjny Komitet Obywatelski MKO); dies war aber bis 1918 wenig mehr als ein politischer 'Stammtisch<, der einen Informationsaustausch mit den im Westen tätigen Vertretern der Nationaldemokraten und anderer antideutscher Gruppen betrieb. Die Masse der polnischen Bevölkerung war in diese Aktivitäten nicht einbezogen.

\section{8 - militärische Auflösung, soziale Revolution und polnische Konspiration}

Erst nach dem Scheitern der deutschen Frühjahrsoffensive 1918 bzw. nach der Rückführung des deutschen Heeres über den Rhein im November desertierten ethnische Polen in nennenswerter Zahl bzw. wurden regulär demobilisiert und kehrten in ihr Heimatgebiet zurück. Damit waren sie im Prinzip Teil eines allgemeinen Phänomens im damaligen Deutschland; besonders war, dass diese Soldaten durch nationalpolnische Agitatoren dazu aufgefordert wurden, ihre Waffen zu behalten, während viele ethnisch deutsche Soldaten diese wegwarfen oder verkauften ${ }^{48}$.Z weck dieser Maßnahme - deren tatsächlicher Effekt schwer zu messen ist - war es zunächst, in Gestalt polnisch gesinnter fronterfahrener Männer ein Faustpfand für die nach der deutschen Niederlage bevorstehende politische Neuordnung zu besitzen, ohne dass dabei an eine bewaffnete Erhebung gedacht worden wäre. In diesem Sinne wurden die zivilen Politiker in der Provinz seit dem Sommer aktiv. Das erwähnte Interparteiliche Bürgerko-

47 Vgl. Roman Wapiński, Świadomość polityczna w Drugiej Rzeczypospolitej [Politisches Bewusstsein in der Zweiten Republik], Łódź 1989, S. 195.

48 Vgl. etwa Richard Bessel, Die Heimkehr der Soldaten. Das Bild der Frontsoldaten in der Öffentlichkeit der Weimarer Republik. In: >Keiner fühlt sich hier mehr als Mensch...<. Erlebnis und Wirkung des Ersten Weltkriegs, hrsg. von Gerhard Hirschfeld, Gerd Krumeich und Irina Renz, Essen 1993, S. 221-241, hier S. 227-228. 
mitee (MKO) benannte sich im Juli 1918 in Zentrales Bürgerkomitee (Centralny Komitet Obywatelski - CKO) um und bemühte sich - noch immer im Geheimen - darum, die polnische Bevölkerung im Hinblick auf eine mögliche Sezession hinter sich zu scharen. Eine solche Sezession sollte aber auf politischem Wege mit Hilfe der Westmächte erfolgen, zumal ein gewaltsames Vorgehen angesichts der militärischen Kräfteverhältnisse aussichtslos erschien ${ }^{49}$.

Diese nationalistischen, aber taktisch geschickt agierenden politischen Kreise erhielten jedoch Konkurrenz - nicht zuletzt hinsichtlich der Nutzung der kriegserfahrenen Rückkehrer - durch die Vertreter reaktivierter bzw. neuer radikaler Gruppen, teils mit einem Skaut- oder Zet-Hintergrund. Besonders wichtig waren darunter ehemalige preußische (Reserve-)Offiziere wie Mieczysław Paluch und Bohdan Hulewicz. Letzterer hatte 1912 als EinjährigFreiwilliger gedient und war als Leutnant der Reserve ausgeschieden. Später hatte er in München studiert und sich als militärischer Ausbilder der dortigen Zet-Gruppe betätigt ${ }^{50}$. Im Krieg waren sie im aktiven Einsatz an der Westfront (Paluch) bzw. in der Marine (Hulewicz) gewesen. Im Sommer 1918 legal nach Posen zurückgekehrt, traten sie in Kontakt mit den lokalen nationalistischen Kräften und fungierten vermöge ihrer militärischen Erfahrung als Berater, obwohl sie als Anhänger Piłsudskis auch Misstrauen hervorriefen und neben der Endecja eine selbstständige Gruppe bildeten. Sie loteten in jeder Phase des Geschehens die Möglichkeiten eines bewaffneten Vorgehens aus. Einen dritten wichtigen Faktor hinsichtlich der militärischen Dimension der polnischen Irredenta bildete die Ende 1917 gegründete Polnische Militärorganisation des preußischen Teilungsgebiets (Polska Organizacja Wojskowa Zaboru Pruskiego - POWZP) unter Leitung des Skauting-Veterans Wincenty Wierzejewski. Obwohl im Namen an die schon länger in Russisch-Polen und Galizien tätige, Piłsudski unterstehende POW erinnernd, lehnte diese Posensche Gruppe jede selbst taktische Zusammenarbeit mit Deutschland ab und distanzierte sich zugleich vom in den Legionen gepflegten Führerkult um Piłsudski. Der Kontakt mit der POW sowie mit dem im Oktober 1918 entstehenden Stab der Polnischen Armee bedeutete daher keine Unterordnung ${ }^{51}$. Allerdings stießen jenseits der Grenze offenbar mehrere hundert demobilisierte Soldaten des deutschen Heeres zur entstehenden Polnischen Armee ${ }^{52}$. Über die kleine, aber »national« hochmotivierte POWZP (sie zählte maximal 400-500 Mann) übernahm am 12. November im Namen des CKO Paluch die Kontrolle, um ein eigenmächtiges Handeln zu verhindern, aber auch, um sie ggf. selbst einzuset$z n^{53}$. Dies war ihm hauptsächlich durch die Funktion möglich, die er ab dem

49 Vgl. Jerzy Kozłowski, Wielkopolska pod pruskim zaborem w latach 1815-1918 [Großpolen unter preußischer Herrschaft in den Jahren 1815-1918], Poznań 2004, S. 282.

50 Vgl. Karwat, Od idei do czynu (wie Anm. 34), S. 266 f.

51 Vgl. ebd., S. 320-323.

52 Vgl. Schreiben des Generalstabs der Polnischen Armee an die polnischen territorialen Militärbehörden bzgl. der Annahme sich meldender Posener, Warschau, 3.11.1918. In: Walka o polską granicę zachodnią 1918-1921. Wybór źródeł, hrsg. von Bogusław Polak, Koszalin 1993, Nr. 2, S. $7 \mathrm{f}$.

53 Vgl. Karwat, Od idei do czynu (wie Anm. 34), S. 377. 
14. November im Vollzugsausschuss des Posener Arbeiter- und Soldatenrats ausübte.

Die am 9. November in Deutschland ausgebrochene Revolution wirkte beschleunigend auf die politischen Prozesse in der Provinz Posen, in erster Linie durch die Unterminierung der öffentlichen Gewalt bzw. deren Ablösung durch revolutionäre Gremien. Während dies im deutschen Kerngebiet eine soziale Auseinandersetzung war und dementsprechend dem klassischen RechtsLinks-Schema folgte, bedeutete sie in den gemischt besiedelten Gebieten des Ostens - jedenfalls aus nationalpolnischer Sicht - primär den Auslöser für einen Prozess der nationalen Differenzierung bis hin zur Separation. Diese >Ungleichzeitigkeit des Gleichzeitigen< wurde von den revolutionären deutschen Kräften nicht oder zu spät erkannt. Obwohl die in Posen tonangebenden, sozial konservativen Nationaldemokraten früh deutlich machten, dass sie an keiner sozialen Revolution interessiert, sondern vielmehr bestrebt waren, die Revolution der deutschen Kriegsverlierer für ihre eigene nationale Revolution auszunutzen ${ }^{54}$ (und somit eine konservative deutsche durch eine konservative polnische Ordnung zu ersetzen), nahmen linke und liberale Kräfte in Deutschland diesen Unterschied nicht wahr und sahen in den Polen irrigerweise Verbündete im Kampf gegen den »preußischen Autoritarismus«. Daher duldeten sie nicht nur die Bürgerkomitees - seit Mitte November Volksräte (Rady Ludowe) - als lokale Interessenvertretungen der Polen, sondern ließen es auch $\mathrm{zu}$, dass die Bürgerwebren (Straży Obywatelskie), die nach einer Idee des preußischen Innenministeriums angesichts der unsicheren Situation des Reiches eigentlich paritätisch die öffentliche Ordnung sichern sollten, schnell von den Polen dominiert wurden.

Das skizzierte Vorgehen blieb für die gesamte Folgezeit bis 1919 die Strategie der Polen: Sie versicherten gegenüber den preußischen und Reichsbehörden ihre gesetzestreue Mitarbeit zur Sicherung von Ruhe und Ordnung sowie ihre Unterstützung der revolutionären Errungenschaften. Tatsächlich betrieben sie unter Ausnutzung der allgemeinen Verwirrung die systematische Majorisierung der Deutschen in allen revolutionär-demokratischen< Gremien und Strukturen der öffentlichen Gewalt, um die Provinz zu polonisieren und de facto bereits aus dem deutschen Staatsverband herauszulösen. Dabei sahen sie im Vorhandensein lokaler deutscher Bevölkerungsmehrheiten lediglich ein technisches, durch alle sich bietenden Mittel zu überwindendes Problem ${ }^{55}$. Zugleich wurden alle sich gegen die polnischen Bestrebungen richtenden deutschen Kräfte gegenüber den deutschen Behörden als »reaktionär«denunziert ${ }^{56}$.

54 So der Endecja-Politiker Władysław Seyda Anfang Dezember 1918, vgl. Vogt, Großpolnischer Aufstand (wie Anm. 10), S. 22. Zur (angeblich) »nationalen« Haltung aller Polen vgl. Witold Łukaszewicz, Ogólna charakterystyka Rad Robotniczo-Żołnierskich i Chłopskich w Wielkopolsce i na Pomorzu Gdańskim 1918-1920 [Allgemeine Charakteristik der Arbeiter-, Soldatenund Bauernräte in Großpolen und Westpreußen 1918-1920]. In: Witold Łukaszewicz, Jacek Staszewski, Mieczysław Wojciechowski, Z dziejów rad robotniczo-żołnierskich w Wielkopolsce i na Pomorzu Gdańskim, Poznań-Bydgoszcz-Gdańsk-Toruń 1918-1920, Poznań 1962, S. 15-59, hier S. 33 und 41.

55 Vgl. Kozłowski, Wielkopolska (wie Anm. 49), S. 286.

56 Vgl. Vogt, Großpolnischer Aufstand (wie Anm. 10), S. 31 
Entscheidend war letztlich die Entwicklung jener Körperschaften, von denen die physische Machtausübung abhing; wie sich zeigen sollte, arbeitete die deutsche Revolution dem polnischen Nationalismus effektiv fast überall in die Hände.

Schon ab dem 7. November entstand, wie im übrigen Reich, in den Ostprovinzen, ausgehend von den Küstengarnisonen in Westpreußen, schnell ein Netz aus Soldatenräten bzw. Arbeiter- und Soldatenräten (A- und S-Räten) $)^{57}$; in Posen entstand der lokale Soldatenrat am 9./10. November im Kernwerk, der zentralen Festung. Eine dessen erster Amtshandlungen war die Anerkennung der polnisch beherrschten Bürgerwebren, die sich - was die deutschen Angehörigen des Rates freilich nicht wussten - damals unter anderem mit der Registrierung aus dem Felde heimkehrender ethnischer Polen beschäftigten. Die besonders wichtige Posener Bürgerwehr stand unter der Leitung des ehemaligen Sokót-Aktivisten Julian Lange. Entscheidend war aber, dass der Soldatenrat - wie in den anderen Hauptorten der preußischen Korpsbezirke - die Aufsicht über das Stellvertretende Generalkommando des V. Armeekorps ausübte. Am 11. November ging das bis dahin geheim gewesene Zentrale Bürgerkomitee zu offener Tätigkeit über und benannte sich in Oberster [Polnischer] Volksrat (Naczelna Rada Ludowa - NRL) um; dessen aus den Politikern Stanisław Adamski, Wojciech Korfanty und Adam Poszwiński bestehendes Kommissariat betrachtete sich als faktische Stadtregierung.

Die polnischen Angehörigen des Posener Arbeiterrates, der sich am 11. November mit dem Soldatenrat verband, gehörten überwiegend auch dem $N R L$ an und waren durchweg keine Arbeiter. Generell saßen der Nomenklatur zum Trotz von polnischer Seite in vielen »Arbeiterräten « infolge der gesellschaftlichen Struktur und der politischen Kräfteverteilung nur wenige Arbeiter; vielmehr waren bürgerliche Kräfte, Grundbesitzer sowie Pfarrer und somit die rechten Parteien tonangebend. Außerdem überwog mit der Zeit fast durchweg das zivile Element gegenüber dem militärischen und - im Ergebnis der beschriebenen polnischen Aktivität, mit Ausnahme der mehrheitlich deutschen Grenzkreise der Provinz - das polnische gegenüber dem deutschen ${ }^{58}$.

In der Folge führte der NRL mehrere Aktionen durch, durch die er die revolutionäre Unruhe dazu nutzen wollte, seinen Herrschaftsanspruch in Posen durchzusetzen: Am 12. November erklärte der A- und S-Rat auf polnisches Drängen hin den deutschen Oberbürgermeister Dr. Ernst Wilms für abgesetzt und setzte stattdessen den Polen Jarogniew Drwęski ein ${ }^{59}$; dabei berief er sich auf die nach Aufhebung des Dreiklassenwahlrechts bestehenden Mehrheitsverhältnisse. Am 13. November stürmten während einer Sitzung des A- und S-Rates im Posener Rathaus polnische Soldaten den Sitzungssaal und forderten ultimativ eine Erhöhung der Zahl der Polen im Rat. Tatsächlich kam es infolge dieser erzwungenen Änderung zu einem polnischen Übergewicht; konkret

57 Hierzu vgl. allgemein Carsten, Revolution (wie Anm. 13), S. 115-141, sowie Łukaszewicz, Ogólna charakterystyka (wie Anm. 51), passim.

58 Vgl. Vogt, Großpolnischer Aufstand (wie Anm. 10), S. 18, sowie Łukaszewicz, Ogólna charakterystyka (wie Anm. 51), S. 40-43.

59 Vgl. Kozłowski, Wielkopolska (wie Anm. 49), S. 285; Karwat, Od idei (wie Anm. 34), S. 350. 
wurden vier deutsche durch vier polnische Mitglieder ersetzt, darunter die erwähnten Offiziere Mieczyslaw Paluch und Bohdan Hulewicz. Letztere saßen danach im maßgeblichen Vollzugsausschuss des A- und S-Rates ${ }^{60}$; von hier wurde Paluch am 14. November als »Dezernent « dem Stellvertretenden Generalkommando des V. Armeekorps beigeordnet ${ }^{61}$. Dadurch hatte er einen privilegierten Überblick über alle militärischen Bewegungen und Maßnahmen im Korpsbezirk; außerdem gehörte er gemeinsam mit Hulewicz zur Sicherheitsabteilung des NRL und stand im Kontakt mit dessen Militärabteilung ${ }^{62}$.

Schon am nächsten Tag, dem 15. November, kam ihm dies zugute, als er mit als Erster aus Berlin eine Nachricht des preußischen Kriegsministeriums über zwei Maßnahmen erhielt, mittels derer die Regierung die Sicherheit im Osten gewährleisten wollte: erstens durch die Einrichtung eines Heimatschutzes Ost, zweitens durch die Errichtung eines Wach- und Sicherungsdienstes in Kompaniestärke (sog. W- und S-Kompanien) in den Garnisonsstädten. Diese beruhten auf der Einschätzung der Obersten Heeresleitung (OHL), die Ostgrenze müsse angesichts der schwierigen Lage während des deutschen Rückzugs aus dem Baltikum und Russland sowie angesichts der Bolschewistengefahr gesichert werden, dies sei aber infolge der Auflösung des Heeres nur durch Heranziehung von Freiwilligenverbänden möglich. Der Heimatschutz sollte dabei eine von der OHL geführte Truppe für den gesamten östlichen Grenzraum bilden, die Wach-und Sicherbeitskompanien hingegen den lokalen Militärbehörden unterstellt werden. Paluch reagierte auf diese Informationen entsprechend seinen militärisch-politischen Ambitionen: Der Heimatschutz wäre personell und strukturell von den Polen nicht zu kontrollieren und würde jede polnische militärische Aktivität be- oder verhindern. Daher führte des A- und S-Rat am 17. November eine Sitzung zu diesem Thema durch und entsandte eine Delegation nach Berlin. Als daraufhin am 19. November der Unterstaatssekretär im Reichsinnenministerium Hellmut von Gerlach in Posen weilte, wiederholte Paluch namens des Vollzugsausschusses des A- und S-Rates die Forderung, die Regierung möge auf die Aufstellung des Heimatschutzes verzichten; man könne schließlich die Sicherheit mittels der gerade im Aufbau befindlichen $W$ - und S-Kompanien gewährleisten ${ }^{63}$. Gerlach, der gegenüber den polnischen Forderungen nach Erkennung der faits accomplis generell nachgiebig war, ging auf diese Argumentation ein, obwohl sie dem Sinn der betreffenden Maßnahmen zuwiderlief: Heimatschutz und W- und S-Kompanien waren als komplementäre Elemente gedacht und nicht als Alternativen.

Ihm wurden später massive Vorwürfe gemacht, weil er den Versicherungen so leichtfertig geglaubt und sein allzu optimistischer Bericht an die Berliner Regierung ein damals noch mögliches Einschreiten gegen die polnische Irre-

60 Die Liste der Mitglieder bei Vogt, Großpolnischer Aufstand (wie Anm. 10), S. 31.

61 Vgl. Karwat, Od idei (wie Anm. 34), S. 377 f., sowie Vogt, Großpolnischer Aufstand (wie Anm. 10), S. $18 \mathrm{f}$.

62 Vgl. Czubiński, Powstanie (wie Anm. 27), S. 69.

63 Vgl. Vogt, Großpolnischer Aufstand (wie Anm. 10), S. 25 f., sowie Bogusław Polak, Walki powstańcze w Poznaniu (17 XII 1918 - 6 I 1919) [Die Aufstandskämpfe in Posen (17.12.19186.1.1919)]. In: Kronika Miasta Poznania 54 (1986), Nr. 4, S. 33-51, hier S. 35. 
denta verhindert habe. Das betrifft vor allem sein Eingehen auf die polnische Forderung, keine »fremden « Truppen, d.h. solche von außerhalb Posens, in die Provinz zu schicken ${ }^{64}$; dabei war klar, dass die Verwendung allein »bodenständiger " Truppen eine ethnisch polnische Mehrheit mit sich bringen und das polnische Machtstreben unterstützen musste. In der Tat war Gerlach als liberaler Kritiker der Polenpolitik der Vorkriegszeit gegenüber den Polen positiv disponiert und nahm daher deren separatistische Haltung nicht zur Kenntnis, die jede Annahme eines gemeinsamen »revolutionären « Interesses ad absurdum führte ${ }^{65}$. Allerdings müssen ihm zwei Dinge zugutegehalten werden: Zum einen war sein Handeln von dem Primat geleitet, die Nahrungszufuhr aus Posen ins Reich zu sichern und dabei jeden Konflikt zu vermeiden, der die Ententemächte auf den Plan rufen könnte ${ }^{66}$; und zum anderen waren es die Militär- und Zivilbeamten vor Ort, die - aus Gründen, die sich einer endgültigen Analyse wohl entziehen - die Situation als sicher einschätzten und Gerlach dazu rieten, auf die Forderungen der Polen einzugehen. So berichtete Gerlach, noch nach seiner Abreise habe ihm der Stellvertretende Kommandierende General, von Bock und Polach, seinen Adjutanten mit der Bitte hinterhergeschickt, etwa geplante Truppenverlegungen aus Berlin zu verhindern ${ }^{67}$. Dieser und andere Verantwortliche besaßen offenbar keinerlei Kenntnis von den im Gange befindlichen konspirativen Aktionen der polnischen Radikalen um Paluch.

Der Heimatschutz Ost wurde zwar aufgestellt, aber schon Mitte Dezember 1918 durch den Grenzschutz Ost abgelöst, allerdings nicht aufgrund der polnischen Forderung, sondern wegen der schweren Führbarkeit der oft undisziplinierten Männer. Ihr Recht auf den Schutz der eigenen Staatsgrenze gab freilich auch die revolutionäre Reichsregierung - trotz eines nochmaligen Interventionsversuchs der Posener Polen unter Leitung Paluchs Anfang Dezember $^{68}$ - nicht auf. Der Grenzschutz wurde zu einem wesentlich effektiveren Instrument des Landesschutzes unter den Bedingungen des Waffenstillstands, nicht zuletzt, weil der hemmende Einfluss der A- und S-Räte unter dem Eindruck der polnischen Aktivitäten allmählich nachließ ${ }^{69}$. Somit drangen die Polen zwar nicht mit ihrem Wunsch nach einer faktischen deutschen Preisgabe der Ostgrenze durch; dafür konnten sie das andere in Berlin zur Sicherung des östlichen Grenzraums erdachte Element in ihrem Sinne entwickeln.

${ }^{64}$ Vgl. Hellmut von Gerlach, Von rechts nach links, ND Frankfurt a. M. 1987, S. 232; Baier, Deutscher Osten (wie Anm. 11), S. 193.

65 Vgl. ebd., S. 230.

66 Vgl. Baier, Deutscher Osten (wie Anm. 11), S. 192.

67 Vgl. Hellmut von Gerlach, Der Zusammenbruch der deutschen Polenpolitik, Berlin 1919, S. 12.

68 Vgl. Vogt, Großpolnischer Aufstand (wie Anm. 10), S. 28.

69 Vgl. Carsten, Revolution (wie Anm. 13), S. 220-222. 


\section{Das (halb)konspirative Netzwerk}

Die beschriebenen Entwicklungen zeigten ein Muster äußerlich legaler und als (vermeintliche) Elemente der >revolutionären Neuordnung zu sehender Verschiebungen im lokalen bzw. regionalen Machtgefüge vor allem der Provinz Posen. Der größte Teil dieser von der polnischen Seite gleichsam sgekaperten Prozesse war für die deutschen und preußischen Behörden grundsätzlich offen beobachtbar; wenn diese den wahren, $\mathrm{d}$. h. nationalrevolutionären Charakter der polnischen Aktivitäten nicht erkannten, so lag dies in erster Linie an ihrer durch subjektive Voreingenommenheit getrübten Wahrnehmung.

Den >offenen< Bereich dieser polnischen Bestrebungen zum faktischen Transfer der Macht deckten die zivilen Führungsgruppen in den polnischen Parteien und gesellschaftlichen Organisationen ab, indem sie die noch immer preußisch-deutschen öffentlichen Ämter mit >ihren< Leuten besetzten und die Kommunikation mit den zentralen Behörden an sich zogen; dadurch hatte der deutsche Bevölkerungsteil immer weniger Möglichkeiten, sich mit jenen direkt $\mathrm{zu}$ verständigen. Zugleich bereiteten die zivilen polnischen Akteure den Rahmen für die Tätigkeit der polnischen (para)militärischen Gruppen; diese bildeten sozusagen den Bereich sechter< Konspiration, da sie im Geheimen und mit solchen Mitteln auf eine polnische Machtübernahme in Posen (bzw. auch in anderen Gebieten) hinarbeiteten, deren offenes Zutagetreten selbst die in der beschriebenen Weise indolenten Behörden alarmiert hätte.

Ihr Gewicht verlieh den militärischen Akteuren wohl weniger eine völlige Kongruenz ihrer Ziele mit denjenigen der Politiker - tatsächlich waren letztere nie vollständig über die Einzelheiten der militärischen Konspiration informiert und lehnten teilweise ein gewaltsames Vorgehen überhaupt ab. Vielmehr kam die sich in der Endphase des Krieges entwickelnde besondere Dynamik zum Tragen, in der die Polen (und andere Völker) nach Eigenstaatlichkeit strebten, wofür die Erlangung militärischer Fähigkeiten und Positionen als ein unabdingbares Unterpfand galt. Entsprechend großen Einfluss konnten kriegserfahrene Soldaten erlangen: Sie kannten die Armee der jeweiligen »Teilungsmacht « und waren bereit, gegebenenfalls gegen diese oder auch andere potenzielle Gegner neue Kriege zu führen (dies war zugleich die strukturelle und mentale Basis für zahlreiche Bürgerkriege und andere Nachkriegskonflikte ${ }^{70}$ ).

Kraft seiner Position im Vollzugsausschuss des A- und S-Rates sowie beim Stellvertretenden Generalkommando sorgte Mieczysław Paluch dafür, dass die wie die Bürgerwehren eigentlich paritätisch konzipierten W- und S-Kompanien im Bereich des V. Armeekorps zu faktisch polnischen - allerdings durch den deutschen Staat finanzierten ${ }^{71}-$ Einheiten wurden ${ }^{72}$. Bemerkenswert ist, dass

70 Hierzu vgl. die Beiträge in Krieg im Frieden (wie Anm. 15).

71 Mannschaften erhielten monatlich 120 Mark plus Ausrüstung und Verpflegung, Offiziere sogar 180 Mark. Vgl. Polak, Walki powstańcze (wie Anm. 63), hier S. 36, Anm. 7.

72 So bezeichnete ein Bericht vom 24.12. an den polnischen Generalstab in Warschau den Sicherungsdienst und die Volkswehr als »polnische bewaffnete Kräfte«. Vgl. Meldung des Majors Ignacy Matuszewski vom 24.12.1918 an den Generalstab über die militärische Lage im preußi- 
ein von Bohdan Hulewicz verfasster und auch von seinen deutschen Mitgliedern unterzeichneter Aufruf des Vollzugsausschusses des A- und S-Rates vom 23. November allein die polnischen ehemaligen Angehörigen der preußischen Armee zum Eintritt in die neuen Einheiten aufrief und dabei gegen den $\mathrm{Hei}$ matschutz polemisierte, der schließlich ebenfalls eine offizielle staatliche Einrichtung war ${ }^{73}$. Hier wirkten sich offenbar die ideologischen Vorbehalte der sozialistischen deutschen Mitglieder gegenüber dem konservativen deutschen Milieu der Provinz noch immer dahingehend aus, dass sie die polnischen Initiativen als 'Schutz der Revolution< interpretierten.

Während in der Folge für die sich bildenden W- und S-Kompanien Polen gern genommen und auch angeworben wurden, suchten Paluch und die übrigen Leitenden deutsche Freiwillige - an die in Berlin natürlich auch und sogar vor allem gedacht worden war - unter Vorwänden vom Eintritt abzuhalten. So wurde deutschen Soldaten, die nicht aus der Provinz stammten, nahegelegt, sie sollten sich in diesen unruhigen Zeiten um ihre Familien in der Heimat kümmern. Daher stellten die unter polnischer Kontrolle stehenden Militärbehörden solchen Soldaten bevorzugt Entlassungs- bzw. Urlaubspapiere aus ${ }^{74}$; die Nachfrage hiernach stieg im Dezember 1918 angesichts der sich nähernden Weihnachtstage. Im Ergebnis wurden die W- und S-Kompanien zu den Hauptsammelstellen der sich aufgrund der nationalpolnischen Propaganda zur Verfügung stellenden polnischen Frontheimkehrer. Diese waren in der Regel zwischen 24 und 28 Jahre alt und zumindest teilweise vor dem Krieg Mitglieder paramilitärischer Gruppen gewesen ${ }^{75}$. Die Zuführung der sich meldenden Freiwilligen erfolgte überwiegend durch die Posener Volkswebr. Angeblich meldeten sich in deren Werbebüro in der Kaiser-Wilhelm-Bibliothek damals täglich 20-30 Freiwillige ${ }^{76}$.

Ebenfalls in den Händen der Posener Volkswehr lag die Disposition über die Einquartierung der neuen Truppe. Da die W- und S-Kompanien offizielle Organe waren, die theoretisch mit den Einheiten des Heeres zusammenwirken sollten, erhielten sie ihr Quartier unter anderem in zwei der die Stadt sichernden Forts - Rauch und Prittwitz - sowie in der Kaserne des 47. Infanterieregiments. Als erstes wurden dort zwei schon bestehende informelle Gruppen der POWZP einquartiert, die kurzerhand in $W$ - und S-Kompanien umdefiniert wurden. Lediglich in der Zitadelle (Kernwerk) gelang keine Einschleusung solcher Einheiten; allerdings erhielten die Verschwörer Zugriff auf die Informationen, die von der dort befindlichen Radiotelegraphenstation abgingen bzw. dort eingingen. In Posen ankommende Spezialkuriere der deutschen Behörden wurden sogar schon seit Juli 1918 von einem im Operationsstab des V.

schen Teilungsgebiet. In: Walka o polską granicę zachodnią 1918-1921. Wybór źródeł, hrsg. von Bogusław Polak, Koszalin 1993, Nr. 11, S. 19-22.

73 Vgl. Karwat, Od idei (wie Anm. 34), S. 367 f. Es scheint, dass analoge Aufrufe auch auf Deutsch verfasst wurden; deren Wortlaut ist jedoch nicht bekannt.

74 Vgl. Karwat, Od idei (wie Anm. 34), S. 360 f.

75 Vgl. Bogusław Polak, Wojsko wielkopolskie w latach 1918-1920 [Das großpolnische Heer in den Jahren 1919-1920]. In: Kronika Miasta Poznania 56 (1988), 1, S. 41-71, hier S. 47.

76 Vgl. Karwat, Od idei (wie Anm. 34), S. 369. 
Armeekorps tätigen Angehörigen der POWZP heimlich ausgewertet. Überdies wirkten in den in Posen angesiedelten Behörden der preußischen Militärverwaltung zahlreiche polnische Zivilangestellte daraufhin, die Magazininhalte und andere Versorgungsgüter vor der Ausfuhr nach Westen zu bewahren und diese sowie die militärischen Kommunikationswege ggf. polnischen Aufständischen zuzuführen ${ }^{77}$.

Unter den ersten Zuflüssen in die W- und S-Kompanien von außen waren zahlreiche ehemalige Marineangehörige, die teils aus den deutschen Küstenstandorten, teils von der Ostfront nach Posen kamen. Anfang Dezember erfolgte der Beschluss zur Aufstellung von vier Kompanien, die vorrangig aus Matrosen bestehen sollten. Bis Ende Dezember wurden insgesamt neun W- und S-Kompanien aufgestellt. Paluch übte den Oberbefehl über all diese Einheiten aus, wobei erneut eine Überlappung seiner Beziehungen zum NRL einerseits, zum A- und S-Rat andererseits bestand. Als Schaltstelle für die W- und SKompanien sowie auch die illegalen bewaffneten Gruppen entstand um den 15. Dezember herum unter Paluchs und Hulewiczs Leitung eine »Kommandantur " $(k o m e n d a ~ w o j s k o w a)^{78}$. Ihre weiterreichenden Pläne zur Schaffung eines "Stabes « sowie eines regulären Militärkaders in Posen ${ }^{79}$ waren mehr Wunschdenken als realistisch, gleichwohl gelang ihnen die Zusammenführung der (begrenzten) vorhandenen Kräfte. Wichtig war auch der seit Anfang Dezember regelmäßig - und teils am nationaldemokratischen $N R L$ vorbei durchgeführte Informationsaustausch mit dem Generalstab in Warschau ${ }^{80}$.

Am Vorabend des Aufstands zählten gemäß den verfügbaren Zahlen die Bürgerwebren, die seit Ende November als Volkswebren (Straży Ludowe) bezeichnet wurden, in der Stadt Posen ca. 4800 Mann - davon allerdings nur 2650 bewaffnet - und in der übrigen Provinz ca. 3000 Mann. Die W- und SKompanien umfassten im Dezember 1918 ca. 775 bewaffnete Angehörige, bei ca. 2000 eingetragenen Mitgliedern ${ }^{81}$. Ein bleibendes Problem für ihren möglichen Einsatz war ein genereller Mangel an erfahrenen militärischen Führern. Zum Zeitpunkt der deutschen Revolution waren die meisten Soldaten noch bei ihren Einheiten oder auf dem Weg in die Heimat; außerdem konnten Polen in der preußischen Armee ohnehin höchstens bis zum Rang eines Hauptmanns avancieren. Daher gab es zwar viele erfahrene Unteroffiziere und Mannschaften, aber kaum Offiziere mit der Fähigkeit zur Führung größerer Verbände ${ }^{82}$.

Auch unter dem Vorbehalt der nie ganz geklärten Ereignisse des Aufstands kann dennoch gesagt werden, dass es die W- und S-Kompanien - und einige kleinere Gruppen - waren, die auf Paluchs Befehl hin am 27. Dezember 1918 die deutschen Truppen angriffen und dass es vor allem der Überraschungseffekt war, der ihren Erfolg ausmachte. Diese Aktion war geplant gewesen; das in der polnischen Literatur meist als »Provokation« bezeichnete deutsche Herunter-

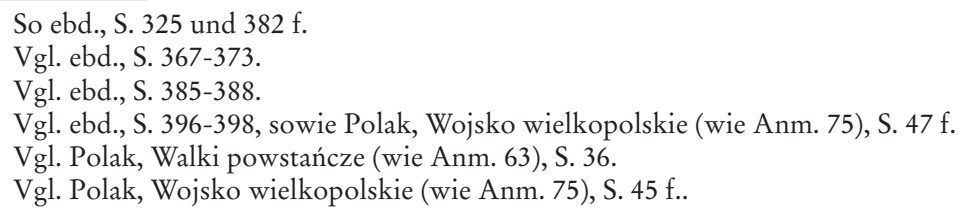


reißen der von den Polen aufgehängten Fahnen der Ententemächte war ein bewusst von jenen polnischen Kräften provozierter Vorwand. Ganz abgesehen von der eingangs gemachten Bemerkung über das Irreale eines »spontanen« Aufstands deutet auf einen planvollen Charakter der bewaffneten Aktion der Polen der Umstand hin, dass sie gleichzeitig in verschiedenen Orten der Provinz stattfand, wo lokale W- und S-Kompanien, polnisch dominierte A- und S-Räte und/oder Abteilungen der Volkswehren von Paluch instruiert worden waren.

Wie bereits erwähnt, besteht keine völlige Klarheit hinsichtlich des Deckungsgrades zwischen den »politischen «Zielen der Endecja und den » militärischen " der unabhängigen Aktivisten um Paluch, Hulewicz und Wierzejewski. Das von der polnischen Literatur gezeichnete Bild schwankt diesbezüglich zwischen einer arbeitsteiligen Kooperation unter Anerkennung der unterschiedlichen Ansichten bzw. Charaktere einerseits und einem angespannten Konkurrenzverhältnis andererseits, in dem sich die >gemäßigten< Nationaldemokraten ständig vor unbedachten Aktionen ihrer militanten Verbündeten fürchteten, welche ihrerseits das sschlappe< Taktieren der Politiker verachteten $^{83}$. Entscheidend dürfte gewesen sein, dass Paluch und Hulewicz dazu imstande waren, verschiedene militante Gruppen unter ihre Kontrolle zu bringen und dem >Reservoir an kampffähigen Männern zuzuführen. Jedenfalls liefen bei diesen beiden die wesentlichen Fäden der militärischen Kontrolle in Stadt und Provinz Posen zusammen: die Aufsicht über das Stellvertretende Generalkommando des V. Armeekorps im Namen des Vollzugsausschusses des A- und S-Rates; die Kontrolle der Wach- und Sicherungskompanien; die Kooperation mit den Bürgerwebren bzw. Volkswebren; die faktische Kontrolle der POWZP sowie die Verbindung mit der Militärabteilung des Obersten Polnischen Volksrats.

Die Entscheidung für den Aufstand zu diesem Zeitpunkt ist wohl auf mehrere einander verstärkende Faktoren zurückzuführen: Die radikale Gruppe um Paluch und Hulewicz wollte militärisch vorgehen, um Posen unter polnische Kontrolle zu bringen, solange die deutsche Seite im Osten keine schlagkräftige Struktur besaß (was sich im Dezember aber abzuzeichnen begann); indirekt ging es ihr wohl auch darum, der Warschauer Piłsudski-Regierung in Posen Einfluss zu verschaffen. Die Endecja sah ein gewaltsames Vorgehen zwar als riskant an, wurde aber durch die französische Führung dazu ermutigt, vollendete Tatsachen zu schaffen; auch wollte sie nicht riskieren, in der national aufgeputschten Bevölkerung als unentschlossen zu erscheinen. Schließlich ermutigte die erkennbare Arg- bzw. Hilflosigkeit der preußischen Militär- und Zivilbehörden gegenüber den - teils recht offensichtlichen - Vorbereitungen der Polen diese zum Handeln.

Tatsächlich hatte die polnische »Konspiration« in Posen nur teilweise einen verdeckten Charakter; zum anderen Teil erfolgte sie praktisch offen. Neben tatsächlich geheimen Aktionen wirkten, wie zu sehen ist, mehrere Umstände als >Schleier<, die es den nationalpolnisch motivierten Verschwörern erleichterten, für die preußischen Behörden gleichsam unsichtbar zu bleiben:

83 Vgl. etwa Czubiński, Powstanie (wie Anm. 27), S. 69. 
1. Die Autorität der bestehenden Ordnung war durch die Novemberrevolution generell erschüttert worden, wobei die ausgerechnet im Militär ihren Anfang nehmende Insubordination ${ }^{84}$ in den Augen der Vertreter der militärischen und zivilen preußischen Behörden einen besonders eklatanten Bruch mit den gewohnten monarchisch-autoritär geprägten Anschauungsund Verhaltensweisen darstellte. Ebenjene Behörden hatten zwar nach anfänglichen Mühen die Heimatfront während des Krieges einigermaßen zu organisieren verstanden ${ }^{85}$, erwiesen sich jedoch - unter anderem infolge ihres starren Formalismus und Legalismus - als schlecht vorbereitet auf einen Ausnahmezustand, der nicht mehr unmittelbar kriegsbezogen war, sondern eben revolutionären Charakter besaß, sprich die Grundlagen der staatlichen Ordnung umstürzte.

2. Spezifisch für Posen - anfangs kaum für andere Mischgebiete wie Westpreußen und Oberschlesien - war die nationalpolitische Instrumentalisierung der sozialen Revolution durch die polnischen Aktivisten, die dabei effektiv oft durch die - oft ortsfremden - deutschen revolutionären Soldaten begünstigt wurden. In dieser wenig industrialisierten und urbanisierten Region waren linke und liberale Kräfte, die möglicherweise eine vermittelnde Politik hätten tragen können, schwach vertreten, zumal auf der polnischen Seite, wo nationalistische und klerikale Positionen überwogen. Dazu kam die generelle Achsenverschiebung weg von der parteipolitischen hin zu einer nationalen Definition politischer Identität (dazu ist anzumerken, dass diese Tendenz in der »Ostmark « schon vor dem Krieg durch die deutsche Polenpolitik begünstigt worden war). Aufgrund dieser Umstände führte die Revolution im preußischen Osten nicht zu einer substanziellen Modernisierung der sozialen und politischen Verhältnisse, sondern zu einem ethnonational konnotierten Herrschaftswechsel unter der Kontrolle konservativer polnischer Kräfte, die der revolutionären Agenda fernstanden und letztlich die Differenz des politisch-gesellschaftlichen Entwicklungsgrads zwischen Zentrum und Peripherie in Deutschland instrumentalisierten ${ }^{86}$.

3. Zwar gab es im Heer kaum ethnisch polnische Offiziere, die bei einem Aufstand für Führungsaufgaben geeignet gewesen wären, aber die Militärbehörden wurden gerade auf den für organisatorische Fragen wichtigen mittleren und unteren Ebenen von frontuntauglich geschriebenen nationalpolnisch gesinnten Unteroffizieren und Soldaten infiltriert. Allerdings teilten die militärischen Führungskreise ohnehin - infolge ihrer Schulung in der Vorkriegszeit - die weitgehende Blindheit der revolutionären Soldaten

84 Hierzu vgl. den nicht unumstrittenen, aber anregenden Aufsatz von Wilhelm Deist, Verdeckter Militärstreik im Kriegsjahr 1918? In: Der Krieg des kleinen Mannes. Eine Militärgeschichte von unten, hrsg. von Wolfram Wette, München 1992, S. 146-167.

85 Vgl. exemplarisch Wolf-Rüdiger Schrumpf, Territoriale Kommandogewalt und zivile Verwaltungskompetenz im 1. Weltkrieg. Konsens, Kooperation, Konflikt. Eine Studie über die Aktivitäten des stellvertretenden Generalkommandos des VII. Armeekorps und der Mittelbehörden der Provinz Westfalen bei der Versorgung der Zivilbevölkerung, Münster 1995.

86 Zu diesem Modell vgl. Hans-Heinrich Nolte, Europäische Innere Peripherien - Ähnlichkeiten, Unterschiede, Einwände zum Konzept. In: Europäische Innere Peripherien im 20. Jahrhundert, hrsg. von dems., Stuttgart 1997, S. 7-16. 
für die nationale Dimension des Geschehens. Ihre hierdurch begründete Unterschätzung der Gefahr einer polnischen Sezession beeinflusste nicht nur das Verhalten der Zivilbehörden in Preußen und im Reich, sondern verhinderte auch vor Ort jede rechtzeitige Sicherungsmaßnahme im deutschen Sinne. Effektiv verstärkten die aufgestellten Sicherungseinheiten, da "paritätisch « gedacht, aber polnisch kontrolliert, die Machtmittel der polnischen Seite und verliehen zugleich deren Handeln - das gegen den preuBisch-deutschen Staat gerichtet war - formal einen legalen Charakter.

4. In dieser Situation wurde die deutsche Zivilbevölkerung (in der Provinz Posen ca. 40\%) dadurch benachteiligt, dass sie zum einen bis in den Sommer 1918 hinein von den staatlichen Stellen über die hoffnungslose Kriegslage im Unklaren gelassen worden und zum anderen - im Gegensatz zu den Polen - nicht daran gewöhnt war, sich ohne behördliche Anleitung als Gruppe zu organisieren. Daher war sie kaum dazu imstande, angesichts der schleichenden Übernahme der öffentlichen Gewalt durch polnische Aktivisten ihre Interessen zu schützen, zumal die preußischen Behörden dieser Entwicklung faktisch Vorschub leisteten. Diese Erfahrungen flossen später unter anderem in die Programmatik der jungkonservativen Bewegung ein, die sich in ihrer »völkischen Erziehungsarbeit« teilweise am polnischen Vorbild orientierte ${ }^{87}$.

5. Ein weiterer sich nachteilig für die deutsche Seite auswirkender Faktor war die Lähmung der deutschen militärischen und außenpolitischen Fähigkeiten durch die Bestimmungen des Waffenstillstands und die nachfolgende Politik der Westmächte. Deren Vorgaben musste die neue demokratische Reichsregierung nolens volens zumindest tendenziell umsetzen, auch wo dies den eigenen Interessen zuwiderlief, wie etwa nach dem Großpolnischen Aufstand. Hinzu kam bei Akteuren wie Hellmut von Gerlach, die der alten Polenpolitik kritisch gegenübergestanden hatten, eine allzu optimistische Annahme gemeinsamer Interessen mit den Polen, da sie den Unterschied zwischen der urban-sozialen Demokratieidee der deutschen Revolution und der ethnisch-ständischen Denkweise der polnischen Nationaldemokraten nicht erkannten.

6. Schließlich behinderte auch der Umstand die Perzeptions- und Analysefähigkeit der deutschen Seite, dass der integral-nationale Ansatz der deutschen Polenpolitik das Erlernen der polnischen Sprache durch die deutschen Beamten und die deutsche Bevölkerung (jedenfalls im öffentlichen Schulwesen) weitgehend verhindert hatte ${ }^{88}$. In der Folge waren die meisten Deutschen - und zwar gerade diejenigen in höheren Positionen - außerstande, selbst der offenen Kommunikation der Polen zu folgen, geschweige denn deren konspirative Aktivitäten zu erkennen. Dagegen waren die meisten Polen des Deutschen mindestens insoweit mächtig, dass sie sich über das Planen und Handeln der deutschen Seite informieren konnten.

87 So etwa einer der wichtigsten Theoretiker dieser Bewegung, Max Hildebert Boehm, in seinen Werken »Europa Irredenta«, Berlin 1923, S. 155, und »Die deutschen Grenzlande«, Berlin 1925, S. 184.

88 Vgl. Helmut Glück, Die preußisch-polnische Sprachenpolitik, Hamburg 1979, bes. S. 238-259. 


\section{Fazit}

Zusammenfassend lässt sich festhalten, dass der Weg zum Posener bzw. Großpolnischen Aufstand - trotz mancher offenbleibender Fragen über die Details seiner Planung und seines Ablaufs - eine Mischung offener und konspirativer Elemente aufwies, bei welcher der nationalpolitische Gegensatz zwischen Deutschen und Polen zwar im Mittelpunkt stand, aber ebenso die komplexen Motive und Handlungen der verschiedenen auf beiden Seiten aktiven Gruppen. Wie ausgeführt, verfolgte auf polnischer Seite nur eine bestimmte Gruppe, die preußischen Militärangehörigen, ein im eigentlichen Sinn konspiratives Ziel. Dies war auch die einzige Gruppe, die - unter Führung ehemaliger Mitglieder militanter Jugendorganisationen - ein relativ klares Anliegen verfolgte, nämlich die Herstellung einer möglichst großen militärischen Fähigkeit für den Fall einer Konfrontation mit der deutschen Staatsmacht - wobei freilich auch dieser sharte Kern< der Verschwörung die Wahrscheinlichkeit einer solchen Situation nicht konkret vorhersehen konnte.

Hingegen agierten die zivilen polnischen Kräfte (Parteien und Verbände) überwiegend offen - durch politische Agitation, Anträge, Beschlüsse in Gremien usw. - und stellten insofern keine konspirativen Strukturen dar. Dennoch bildeten sie effektiv Elemente einer gegen den preußisch-deutschen Staat gerichteten nationalpolnischen Verschwörung ${ }^{89}$, da ab dem Oktober 1918 ihre Tätigkeit zwar noch im Rahmen der legalen Ordnung erfolgte, aber inhaltlich mindestens auf die Übernahme der öffentlichen Gewalt in der Provinz Posen abzielte, wenn nicht gar auf die Sezession und den Anschluss an den in Warschau gegründeten polnischen Staat. Außerdem deckten die zivilen Akteure - und letztlich praktisch die ganze polnische Bevölkerung - mindestens passiv die militärischen Verschwörer aus nationaler Solidarität, unabhängig von ihrer Haltung zur Idee bewaffneten Handelns, so wie es auch von anderen Fällen ethnisch-kulturell begründeter Segregation regionaler Gesellschaften bekannt ist (z. B. Nordirland, Baskenland usw.).

Hinsichtlich der deutschen Seite ist offensichtlich, dass der Aufstand wesentlich durch politische, kommunikative und gesellschaftliche Defizite auf Seiten der staatlichen Behörden wie auch der deutschen Zivilbevölkerung begünstigt wurde. Über das bloße Moment der Überraschung hinaus - das es angesichts der spätestens im Oktober 1918 offen einsetzenden polnischen Agitation eigentlich gar nicht hätte geben dürfen - nutzten die Polen in erster Linie jene offenkundigen Defizite aus; ihr Handeln war für den preußischdeutschen Staat in extremer Weise abträglich, aber formal legal.

Besonders folgenschwer wirkte sich dabei auf deutscher Seite neben dem allgemein hemmenden Legalismus und Formalismus der Behörden die Über-

89 Seitens der polnischen Historiographie wird diese Verschwörung als nationaler Unabbängigkeitskampf betrachtet und bezeichnet. Das ist subjektiv nachvollziehbar, allerdings findet in Polen eine historische Distanzierung von der Staatsgründungsphase um 1918/19, die jene Vorgänge historisieren und auch eine angemessene Berücksichtigung der deutschen Seite ermöglichen würde, (noch?) kaum statt. 
nahme der öffentlichen Gewalt durch die Militärbehörden im August 1914 aus: Diese waren zu Beginn des Krieges gegenüber den Polen übermäßig misstrauisch gewesen; in der zweiten Kriegshälfte und vor allem in der Endphase ab dem Sommer 1918 - als es dann tatsächlich sezessionistische Bestrebungen gab - scheinen sie aber den Überblick völlig verloren zu haben. Die traditionell »unpolitische« $-\mathrm{d}$. h. royalistisch-konservative - Haltung und die durch die direkte Bindung an die kaiserliche Befehlsgewalt halb-autonome Rechtsstellung des preußischen Offizierskorps ${ }^{90}$, welche ihm in Friedenszeiten ein von den »zivilen « Niederungen abgehobenes Dasein und die Konzentration auf die Gegner jenseits der Reichsgrenzen erlaubte, verwandelte sich (spätestens) jetzt in eine Hypothek mangelnder politischer Urteilskraft und Wahrnehmungsfähigkeit für gesellschaftliche Entwicklungen. Womöglich wollten die Militärbehörden vor allem Spannungen und Unruhen zwischen den Deutschen und Polen verhindern, was ihnen gerade nach heute gültigen normativen Maßstäben positiv anzurechnen wäre. Tatsächlich trugen aber ihre Defensivhaltung und ihre abwiegelnden Stellungnahmen entscheidend dazu bei, die Polen zum Handeln zu ermutigen und zugleich die Reichsregierung am Erkennen der Gefahr für die deutsche Ostgrenze zu hindern. Infolge des Posener Aufstands entstand dort früh eine Bresche, welche die späteren Grenzregelungen zuungunsten Deutschlands im Versailler Vertrag ebenso ermutigte wie die Ausrichtung Polens als Bestandteil des gegen Deutschland gerichteten französischen Bündnissystems.

90 Vgl. Andreas Dietz, Das Primat der Politik in kaiserlicher Armee, Reichswehr, Wehrmacht und Bundeswehr. Rechtliche Sicherungen der Entscheidungsgewalt über Krieg und Frieden zwischen Politik und Militär, Tübingen 2011, S. 65-74. 